\title{
Application of Instrumental Neutron Activation Analysis for Chemical Composition Analysis of Ancient Potteries from Buddhist Sites of Andhra Pradesh: Part I
}

\author{
D. Partha Sarathi, ${ }^{a}$ R. Acharya, ${ }^{b}$ A.G.C. Nair, ${ }^{b}$ S. Lakshminarayana, ${ }^{c}$ N. Lakshmana Das, ${ }^{a}$ and \\ A.V.R. Reddy*,b \\ ${ }^{a}$ College of Science, GITAM, Visakhapatnam - 530 045, India \\ ${ }^{\mathrm{b}}$ Radiochemistry Division, Bhabha Atomic Research Centre, Mumbai - 400 085, India \\ ${ }^{c}$ Department of Nuclear Physics, Andhra University, Visakhapatnam - 530 002, India
}

Received: September 3, 2007; In Final Form: December 28, 2007

Instrumental neutron activation analysis (INAA) using high resolution $\gamma$-ray spectrometry was used to determine concentrations of 20 elements in seven clay pottery samples collected from excavated Buddhist sites of four districts of Andhra Pradesh, India. For determining accuracy of the INAA method, two certified reference materials (CRMs) namely SL-1 and Soil-7 obtained from IAEA were analyzed. For establishing the provenance (same or different origin) of pottery samples, Al to Sc concentration ratio as well as statistical cluster analysis was used. For the cluster analysis, concentration values of selected nine elements namely $\mathrm{Sc}, \mathrm{Cr}, \mathrm{Mn}, \mathrm{Fe}, \mathrm{Co}, \mathrm{Rb}, \mathrm{Cs}, \mathrm{Ba}$, and Hf were used. Soil samples from corresponding sites with known origin were analyzed for the validation of provenance methodology adopted in this study. From these analyses, it was observed that both pottery and soil samples under study belong to four different groups. To the best of our knowledge, the provenance studies of these ancient pottery samples are reported for the first time.

\section{Introduction}

Studies on archaeological artifacts constitute an important area of research to unravel the past human activities like art, culture, and trade. Most of the studies focus on the provenance of the artifacts i.e., whether they belong to same or different origin or group. Archaeologists investigate through the provenance studies whether chosen artifacts belong to the same or different origin. In the provenance studies, archaeological artifacts like pottery, bricks, stones, coins, and paints are investigated. ${ }^{1-4}$ Among these artifacts, potteries are most studied. Studies for provenance are carried out in two ways: either by classifying samples according to their physical characteristics, decoration, and style or by chemical composition analysis. ${ }^{1,2}$ Chemical composition analysis of artifacts is the most important tool for providing useful information like geographical origin and manufacturing techniques. ${ }^{3}$ The chemical composition of a clay pottery is strongly related to the source of clay and recipe of the making. ${ }^{4}$ It is known that the concentrations of major elements like $\mathrm{Si}, \mathrm{Al}, \mathrm{Ca}$, and $\mathrm{Mg}$ may not vary significantly compared to the elements present at trace levels. ${ }^{5}$ The variation of trace elements depends on the place and preparation, and hence determination of concentration of trace elements becomes more important. Groups of elements used for the provenance studies are alkali and alkaline earth elements, transition elements and rare earth elements (REEs). ${ }^{3,6}$ Elements which are non-volatile and immobile, exhibit high stability in clay minerals and therefore are good candidates for cluster analysis as any changes if found could be attributed to composition of making rather than due to migration, mobility and weathering with time. ${ }^{3,6}$ The REEs are used for provenance study due to their similar geochemical properties as well as highly insoluble and immobile nature. The alkali and alkaline earth elements like $\mathrm{Na}, \mathrm{K}, \mathrm{Rb}, \mathrm{Cs}$, and $\mathrm{Ba}$, have similar properties and expected to have correlation among them in clay and pottery samples. Correlations are also reported among the

*Corresponding author. E-mail: avreddy@barc.gov.in. Fax: $+91-22-25505151$ transition elements like Sc, Fe, Co, Cr, Hf, and Mn, which are used for grouping of artifacts. For samples like pottery and bricks, making process involves high temperature treatment of wet/sun-drenched samples through firing. Therefore, ratios of concentrations of non-volatile elements like $\mathrm{Al}$ and Sc or elements having similar geochemical properties like La and Ce are used in the provenance studies of samples like potteries. ${ }^{1,7}$

Elemental composition analysis of artifacts demands reliable results of concentrations at major to trace levels using a sensitive analytical method. Non-destructive nuclear analytical methods like neutron activation analysis (NAA), X-ray fluorescence (XRF) and particle induced X-ray emission (PIXE) have been used for the analysis of archaeological artifacts like potteries. $^{7-14}$ These methods have been applied to different samples with varying degrees of success in terms of sensitivity and multielement capability. Among these methods, instrumental NAA (INAA) is the most used method for determining major, minor, and trace elements due to its high sensitivity, low detection limit, simultaneous multielement capability, negligible matrix interference, and most importantly non-destructive nature, i.e., sample is used as it is received without any chemical dissolution. It is an isotope specific technique based on irradiation of samples using reactor neutrons and measuring the characteristic $\gamma$-radiations emitted by the radioisotope produced in irradiation. Often $\gamma$-spectrometry having HPGe detector coupled to multi-channel analyzer (MCA) is used for radioactivity measurement. Use of high flux research reactor neutrons and high-resolution $\gamma$-ray spectrometry makes the method capable of determining many elements at $\mathrm{mg} \mathrm{kg}^{-1}$ to $\mu \mathrm{g}$ $\mathrm{kg}^{-1}$ level. ${ }^{15,16}$ The added advantage of INAA over other methods is that it allows simultaneous multiple sample irradiation in a reactor in a single run. Chemical analyses together with statistical data treatment are used as valid method for provenance study and have been extensively used in the archaeological investigations. ${ }^{3,6,9}$ Multivariate statistical methods like cluster analyses (CA) and principle component analysis (PCA) are mainly used for this purpose. . $^{3,6,9,10,14}$

In the present study, pottery samples, collected from seven different locations, were analyzed by relative method of INAA 
for their elemental concentrations. IAEA CRMs SL-1 and Soil-7 were analyzed to evaluate the accuracy of the method. Concentrations of 20 elements which include Al, alkali, alkaline earth, and transition elements were used for grouping of the pottery samples. Elemental ratios of $\mathrm{Al}$ and $\mathrm{Sc}$ in pottery samples were used for the preliminary grouping. Statistical cluster analysis was carried out using concentrations of nine key elements ( $\mathrm{Rb}, \mathrm{Cs}, \mathrm{Ba}, \mathrm{Sc}, \mathrm{Cr}, \mathrm{Mn}, \mathrm{Fe}, \mathrm{Co}$, and $\mathrm{Hf}$ ) for establishing the provenance of pottery samples under investigation. Similar studies were carried out for seven soil samples collected from corresponding sites of potteries as a method validation of the adopted provenance study, since soil samples origin was known a priori.

\section{Experimental}

2.1. Sample collection sites. Although archaeologists so far have identified more than one hundred and forty Buddhist sites in Andhra Pradesh, ranging in date from pre-Asoka ( $4^{\text {th }}-3^{\text {rd }}$ century BC) to Vishnukundin times $\left(4^{\text {th }}-5^{\text {th }}\right.$ century AD), stretching from Dantapuram in the North to Nandalur in the South and Kotilingala in the West to Bhattiprolu in the East of Andhra Pradesh, India, ${ }^{17}$ initially only seven important sites were selected. These are excavated Buddhist sites along the sea coast of Visakhapatnam, Srikakulam, and other nearby places of Andhra Pradesh, India. The location map of the sites is shown in Figure 1 and additionally, the names of the places and geological coordinates are given in Table 1.

2.2. Collection of samples. The samples were collected under the supervision of personnel from the Department of Archaeology and Museums, Government of Andhra Pradesh, India. Pottery samples of different shapes, with length of 6-15 $\mathrm{cm}$ weighing about $250 \mathrm{~g}-1 \mathrm{~kg}$ were collected from the above sites. Pottery samples were washed off sticking soil, if any, with water, wiped with soft cloth and sealed in a clean polythene bag with a label. To examine the possibility of correlation of pottery results with soil or clay, sub surface soil samples (about $1 \mathrm{~kg}$ ) were collected from a depth of about $10 \mathrm{~cm}$. Soil samples were sun drenched, pebbles were removed and then sealed in clean polythene bags.

2.3. Sample preparation and irradiation. The samples were powdered using agate pestle and mortar. The samples were dried at $105^{\circ} \mathrm{C}$ in a hot air oven for about $24 \mathrm{~h}$ to remove any moisture content. Sample masses used were in the range of 75-150 mg. Samples were heat-sealed using polythene sheets. Samples were irradiated for $7 \mathrm{~h}$ in E8 irradiation position of swimming pool type APSARA research reactor, Bhabha Atomic Research Centre (BARC), Mumbai for medium and long-lived activation products. The thermal neutron flux at this position was of the order of $5 \times 10^{11} \mathrm{~cm}^{-2} \mathrm{~s}^{-1}$. Short irradiations of 1 min duration with samples of $\sim 10 \mathrm{mg}$ mass were carried out using the pneumatic carrier facility (PCF) of Dhruva research reactor, BARC for the activation products whose halflives are in the range of $2 \mathrm{~min}-3 \mathrm{~h}$. The thermal neutron flux

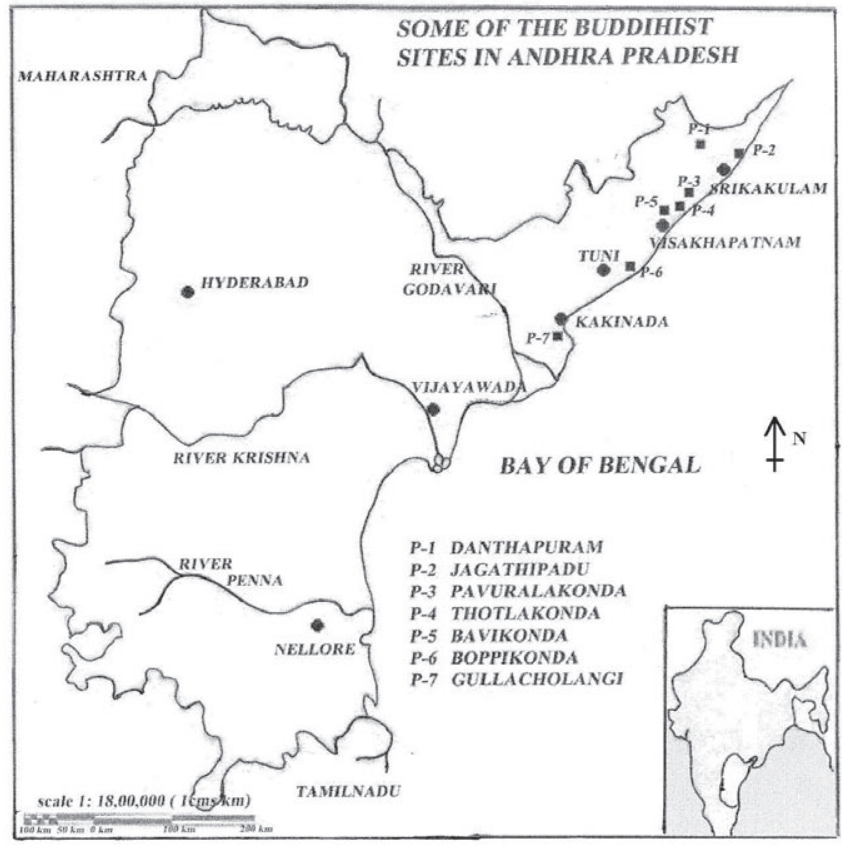

Figure 1. Location map of collection sites of pottery and soil samples.

at this position was of the order of $5 \times 10^{13} \mathrm{~cm}^{-2} \mathrm{~s}^{-1}$. The International Atomic Energy Agency (IAEA) certified reference material (CRM) SL-3 (Lake Sediment) was used as a multielement comparator. Samples along with the multielement comparator were irradiated in different batches. The control samples, CRMs SL-1 and Soil-7 were prepared and irradiated along with multielement comparator in the similar way to that of samples.

2.4. Radioactive assay and calculation of concentration. After appropriate cooling, irradiated samples were mounted on Perspex plates and the radioactive assay was carried out using a $40 \%$ relative efficiency HPGe detector coupled to MCA with $8 \mathrm{k}$ conversion gain. The detector system had a resolution of $2.0 \mathrm{keV}$ at $1332 \mathrm{keV} \gamma$-ray of ${ }^{60} \mathrm{Co}$. The irradiated samples, comparator standard and control samples were counted in identical geometry with respect to the detector. Depending on the half-lives of radioisotopes, elements were divided into three groups. The first group contained short-lived isotopes of elements like Al, $\mathrm{Ca}, \mathrm{Mn}, \mathrm{Ti}$, and $\mathrm{V}$. The second group contained medium-lived isotopes of $\mathrm{As}, \mathrm{Br}, \mathrm{Na}, \mathrm{K}$, and $\mathrm{Ga}$, and the third group contained long-lived isotopes of 10 elements like $\mathrm{Fe}, \mathrm{Cr}$, $\mathrm{Sc}, \mathrm{Cs}$, Hf, and Rb. Measurement times were 60-1800 s for short as well as medium-lived activation products and $2-20 \mathrm{~h}$ for medium and long lived products. The measurement of the radioactivity of first group isotopes was made within 3 min after the end of irradiation. Whereas for second and third groups of elements, measurements began after 1 day cooling

TABLE 1: Name and coordinates of sites chosen for pottery and soil samples

\begin{tabular}{|c|c|c|c|c|c|c|}
\hline S.N. & ID of Pottery & ID of Soil & Site & Location (Town/District) & Latitude & Longitude \\
\hline 1 & $\mathrm{P}-1$ & S-1 & Dantapuram & Srikakulam & $18.15 \mathrm{~N}$ & $84.14 \mathrm{E}$ \\
\hline 2 & $\mathrm{P}-2$ & S-2 & Jagathipadu & Srikakulam & $18.28 \mathrm{~N}$ & $84.28 \mathrm{E}$ \\
\hline 3 & $\mathrm{P}-3$ & $\mathrm{~S}-3$ & Pavuralakonda & Visakhapatnam & $17.53 \mathrm{~N}$ & $83.30 \mathrm{E}$ \\
\hline 4 & $\mathrm{P}-4$ & $\mathrm{~S}-4$ & Thotlakonda & Visakhapatnam & $17.15 \mathrm{~N}$ & $83.23 \mathrm{E}$ \\
\hline 5 & $\mathrm{P}-5$ & $\mathrm{~S}-5$ & Bavikonda & Visakhapatnam & $17.14 \mathrm{~N}$ & $83.25 \mathrm{E}$ \\
\hline 6 & P-6 & S-6 & Boppikonda & Tuni & $17.21 \mathrm{~N}$ & $82.35 \mathrm{E}$ \\
\hline 7 & $\mathrm{P}-7$ & S-7 & Gullacholangi & Kakinada & $16.57 \mathrm{~N}$ & $82.15 \mathrm{E}$ \\
\hline
\end{tabular}


period. The peak areas were evaluated using peak fit software called PHAST, developed at our institute. ${ }^{18}$ Relative method of NAA was used for the calculation of concentrations with an IAEA CRM, SL-3 as reference standard.

\section{Results and Discussion}

The relevant nuclear data were taken from the literature..$^{19,20}$ The concentrations of 20 elements determined from four replicate experiments in all samples and CRMs. The percentage deviations of the determined concentrations in IAEA CRMs SL-1 and Soil-7 are within $\pm 8 \%$. The determined values were in good agreement with their certified or information values. $\mathrm{Z}$-score values in these CRMs were found to be in the range of -2.0 to 1.8 , which are found to be well below the accepted value of \pm 3 .

Results of the elemental concentrations in soil and pottery samples are given in Tables 2 and 3 , respectively. Concentrations of major elements $\mathrm{Al}, \mathrm{Fe}, \mathrm{Ti}, \mathrm{K}, \mathrm{Na}, \mathrm{Mn}$, and $\mathrm{Ba}$ are in the range of 8.0 to $0.03 \%$ whereas other elements are in the $\mathrm{mg} \mathrm{kg}^{-1}$ range. The uncertainties reported in these two tables are due to standard deviations at $\pm 1 \sigma$ confidence level arrived from four independent sample analysis and are within $10 \%$.

Range, grand mean and \% RSD of concentrations for different elements in all the seven pottery samples were calculated and are given in Table 4. This table also gives similarly evaluated data for seven soil samples. It is observed that the mean concentrations of $\mathrm{As}, \mathrm{Br}, \mathrm{Ga}, \mathrm{Co} \mathrm{Hf}, \mathrm{Cs}, \mathrm{Cr}$, and $\mathrm{Sc}$ in potteries are lower than soil samples. Concentrations of rest of the 12 elements in pottery samples are either higher or comparable to that of soil samples. The \%RSD concentrations of all elements of seven pottery samples (column 6, Table 4) vary in the range of $11-80 \%$. Similarly, the \%RSD of concentrations of all ele-

TABLE 2: Concentrations ( $\mathrm{mg} \mathrm{kg}^{-1}$ unless $\mathrm{mg} \mathrm{g}^{-1}$ is indicated) of elements in seven soil samples

\begin{tabular}{cccccccc}
\hline Elements & $\mathrm{S}-1$ & $\mathrm{~S}-2$ & $\mathrm{~S}-3$ & $\mathrm{~S}-4$ & $\mathrm{~S}-5$ & $\mathrm{~S}-6$ & $\mathrm{~S}-7$ \\
\hline $\mathrm{Na}^{*}$ & $2.1 \pm 0.1$ & $3.40 \pm 0.08$ & $1.42 \pm 0.11$ & $1.22 \pm 0.11$ & $1.10 \pm 0.11$ & $2.05 \pm 0.12$ & $6.20 \pm 0.06$ \\
$\mathrm{Al}^{*}$ & $57.5 \pm 2.2$ & $81.6 \pm 1.8$ & $78.6 \pm 1.6$ & $84.6 \pm 1.8$ & $73.4 \pm 1.7$ & $80.3 \pm 2.0$ & $34.6 \pm 2.6$ \\
$\mathrm{~K}^{*}$ & $13.5 \pm 0.4$ & $11.3 \pm 0.8$ & $11.8 \pm 0.7$ & $12.5 \pm 0.5$ & $12.0 \pm 0.6$ & $11.0 \pm 0.8$ & $11.7 \pm 0.7$ \\
$\mathrm{Sc}$ & $8.1 \pm 0.4$ & $10.8 \pm 0.4$ & $20.2 \pm 0.3$ & $21.6 \pm 0.3$ & $19.2 \pm 0.3$ & $26.7 \pm 0.2$ & $21.9 \pm 0.3$ \\
$\mathrm{Ti} *$ & $5.31 \pm 0.24$ & $5.62 \pm 0.24$ & $7.8 \pm 0.2$ & $6.20 \pm 0.32$ & $6.20 \pm 0.32$ & $4.90 \pm 0.33$ & $3.10 \pm 0.34$ \\
$\mathrm{~V}$ & $47.2 \pm 4.2$ & $44.8 \pm 4.4$ & $120.0 \pm 2.5$ & $97.9 \pm 3.5$ & $81.0 \pm 3.9$ & $85.5 \pm 3.8$ & $53.1 \pm 4.1$ \\
$\mathrm{Cr}$ & $64.8 \pm 3.2$ & $60.2 \pm 3.8$ & $174.6 \pm 2.2$ & $185.0 \pm 2.0$ & $193.0 \pm 1.8$ & $81.7 \pm 2.4$ & $46.4 \pm 4.4$ \\
$\mathrm{Mn} *$ & $0.53 \pm 0.04$ & $0.77 \pm 0.03$ & $1.36 \pm 0.02$ & $0.96 \pm 0.03$ & $0.95 \pm 0.03$ & $2.10 \pm 0.05$ & $0.33 \pm 0.15$ \\
$\mathrm{Fe}$ & $28.2 \pm 1.1$ & $27.9 \pm 1.0$ & $54.2 \pm 0.6$ & $59.3 \pm 0.5$ & $61.3 \pm 0.5$ & $42.4 \pm 0.5$ & $24.9 \pm 1.2$ \\
$\mathrm{Co}$ & $12.1 \pm 0.9$ & $13.7 \pm 0.8$ & $20.7 \pm 0.6$ & $21.2 \pm 0.5$ & $20.9 \pm 0.5$ & $12.5 \pm 0.9$ & $9.0 \pm 1.0$ \\
$\mathrm{Ga}$ & $8.3 \pm 1.1$ & $10.8 \pm 1.0$ & $16.4 \pm 0.8$ & $28.8 \pm 0.5$ & $28.3 \pm 0.5$ & $15.4 \pm 1.0$ & $7.9 \pm 1.2$ \\
$\mathrm{As}$ & $9.7 \pm 1.6$ & $11.9 \pm 0.8$ & $11.2 \pm 0.7$ & $17.9 \pm 0.9$ & $17.0 \pm 1.0$ & $7.6 \pm 0.6$ & $3.8 \pm 0.2$ \\
$\mathrm{Br}$ & $2.5 \pm 0.2$ & $6.60 \pm 0.45$ & $6.1 \pm 0.5$ & $7.9 \pm 0.4$ & $7.6 \pm 0.4$ & $6.3 \pm 0.5$ & $4.0 \pm 0.6$ \\
$\mathrm{Rb}$ & $120.0 \pm 2.8$ & $150.0 \pm 2.3$ & $68.5 \pm 3.7$ & $102.0 \pm 3.0$ & $98.0 \pm 3.0$ & $107.8 \pm 2.9$ & $65.3 \pm 3.8$ \\
$\mathrm{Cs}$ & $1.3 \pm 0.1$ & $1.92 \pm 0.12$ & $1.70 \pm 0.15$ & $2.91 \pm 0.22$ & $3.2 \pm 0.2$ & $1.81 \pm 0.12$ & $1.01 \pm 0.09$ \\
$\mathrm{Ba}$ & $0.51 \pm 0.01$ & $0.56 \pm 0.01$ & $0.34 \pm 0.02$ & $0.36 \pm 0.02$ & $0.35 \pm 0.02$ & $0.60 \pm 0.01$ & $0.43 \pm 0.01$ \\
$\mathrm{Hf}$ & $14.2 \pm 1.1$ & $11.5 \pm 1.0$ & $9.6 \pm 0.9$ & $15.2 \pm 1.2$ & $17.0 \pm 1.0$ & $12.8 \pm 1.1$ & $9.20 \pm 0.07$ \\
$\mathrm{Th}$ & $18.6 \pm 0.8$ & $15.4 \pm 1.0$ & $23.4 \pm 0.7$ & $26.9 \pm 0.6$ & $39.0 \pm 0.4$ & $29.5 \pm 0.6$ & $24.6 \pm 0.7$ \\
$\mathrm{U}$ & $1.7 \pm 0.1$ & $1.20 \pm 0.12$ & $1.7 \pm 0.3$ & $2.40 \pm 0.08$ & $1.9 \pm 0.1$ & $1.30 \pm 0.12$ & $1.50 \pm 0.11$ \\
$\mathrm{Al} / \mathrm{Sc}$ & $7099 \pm 536$ & $7556 \pm 326$ & $3891 \pm 98$ & $3917 \pm 100$ & $3823 \pm 107$ & $3007 \pm 78$ & $1580 \pm 156$ \\
\hline
\end{tabular}

$* \mathrm{mg} \mathrm{g}^{-1}$

TABLE 3: Concentrations ( $\mathrm{mg} \mathrm{kg}^{-1}$ unless $\mathrm{mg} \mathrm{g}^{-1}$ is indicated) of elements in seven pottery samples

\begin{tabular}{cccccccc}
\hline Elements & $\mathrm{P}-1$ & \multicolumn{1}{c}{$\mathrm{P}-2$} & $\mathrm{P}-3$ & $\mathrm{P}-4$ & \multicolumn{1}{c}{$\mathrm{P}-5$} & $\mathrm{P}-6$ & $\mathrm{P}-7$ \\
\hline $\mathrm{Na}^{*}$ & $3.02 \pm 0.22$ & $3.9 \pm 0.2$ & $4.5 \pm 0.2$ & $2.31 \pm 0.25$ & $2.1 \pm 0.23$ & $2.90 \pm 0.23$ & $5.8 \pm 0.1$ \\
$\mathrm{Al}^{*}$ & $78.3 \pm 1.6$ & $77.8 \pm 1.4$ & $82.2 \pm 1.5$ & $62.5 \pm 1.4$ & $68.5 \pm 1.4$ & $86.5 \pm 1.5$ & $66.6 \pm 1.8$ \\
$\mathrm{~K}^{*}$ & $20.6 \pm 0.9$ & $23.2 \pm 0.8$ & $18.5 \pm 1.0$ & $14.0 \pm 0.8$ & $15.2 \pm 0.7$ & $18.5 \pm 0.8$ & $8.9 \pm 0.6$ \\
$\mathrm{Ca}$ & $9.1 \pm 0.8$ & $13.1 \pm 1.1$ & $9.5 \pm 0.8$ & $9.6 \pm 0.9$ & $7.6 \pm 0.6$ & $12.5 \pm 1.0$ & $14.4 \pm 1.2$ \\
$\mathrm{Sc}$ & $17.6 \pm 0.5$ & $12.7 \pm 0.8$ & $13.1 \pm 0.8$ & $14.5 \pm 0.7$ & $14.7 \pm 0.7$ & $16.4 \pm 0.6$ & $21.2 \pm 0.5$ \\
$\mathrm{Ti} *$ & $3.6 \pm 0.5$ & $4.3 \pm 0.4$ & $6.7 \pm 0.4$ & $8.2 \pm 0.2$ & $6.31 \pm 0.4$ & $7.6 \pm 0.3$ & $7.2 \pm 0.3$ \\
$\mathrm{~V}$ & $66.7 \pm 2.8$ & $58.0 \pm 3.0$ & $88.2 \pm 2.5$ & $75.4 \pm 2.6$ & $82.9 \pm 2.4$ & $102.5 \pm 2.2$ & $116.9 \pm 2.1$ \\
$\mathrm{Cr}$ & $61.8 \pm 2.4$ & $66.1 \pm 2.9$ & $62.5 \pm 3.0$ & $70.0 \pm 2.7$ & $66.4 \pm 2.6$ & $90.5 \pm 2.2$ & $143.9 \pm 1.4$ \\
$\mathrm{Mn} *$ & $0.47 \pm 0.06$ & $0.62 \pm 0.03$ & $0.66 \pm 0.03$ & $0.62 \pm 0.03$ & $2.70 \pm 0.05$ & $0.91 \pm 0.02$ & $0.85 \pm 0.02$ \\
$\mathrm{Fe}$ & $34.9 \pm 0.8$ & $37.1 \pm 1.0$ & $37.4 \pm 1.0$ & $49.0 \pm 0.7$ & $45.9 \pm 0.6$ & $54.2 \pm 0.6$ & $58.0 \pm 0.5$ \\
$\mathrm{Co}$ & $5.0 \pm 0.3$ & $5.8 \pm 0.3$ & $6.3 \pm 0.3$ & $6.6 \pm 0.2$ & $7.2 \pm 0.3$ & $9.3 \pm 0.3$ & $10.7 \pm 0.6$ \\
$\mathrm{Ga}$ & $12.0 \pm 1.0$ & $11.5 \pm 0.9$ & $11.8 \pm 1.0$ & $11.3 \pm 0.9$ & $10.8 \pm 0.9$ & $13.9 \pm 0.8$ & $9.8 \pm 1.1$ \\
$\mathrm{As}$ & $3.3 \pm 0.2$ & $2.6 \pm 0.2$ & $3.5 \pm 0.2$ & $6.1 \pm 0.1$ & $6.9 \pm 0.1$ & $2.0 \pm 0.2$ & $2.3 \pm 0.2$ \\
$\mathrm{Br}$ & $2.7 \pm 0.2$ & $2.0 \pm 0.2$ & $3.1 \pm 0.3$ & $2.0 \pm 0.2$ & $4.1 \pm 0.3$ & $2.6 \pm 0.2$ & $3.5 \pm 0.3$ \\
$\mathrm{Rb}$ & $162.9 \pm 2.4$ & $188.7 \pm 2.2$ & $94.4 \pm 2.9$ & $93.8 \pm 2.9$ & $85.3 \pm 3.2$ & $91.2 \pm 3.0$ & $55.5 \pm 4.1$ \\
$\mathrm{Cs}$ & $1.5 \pm 0.1$ & $1.7 \pm 0.1$ & $1.3 \pm 0.1$ & $1.2 \pm 0.1$ & $1.3 \pm 0.1$ & $1.2 \pm 0.1$ & $1.5 \pm 0.1$ \\
$\mathrm{Ba} *$ & $1.62 \pm 0.01$ & $0.54 \pm 0.04$ & $0.69 \pm 0.03$ & $0.37 \pm 0.02$ & $0.36 \pm 0.02$ & $0.37 \pm 0.02$ & $0.49 \pm 0.04$ \\
$\mathrm{Hf}$ & $12.8 \pm 0.6$ & $8.8 \pm 0.9$ & $9.5 \pm 0.9$ & $12.8 \pm 0.6$ & $11.6 \pm 0.6$ & $13.2 \pm 0.7$ & $8.1 \pm 1.0$ \\
$\mathrm{Th}$ & $18.0 \pm 1.4$ & $38.2 \pm 0.8$ & $29.3 \pm 1.2$ & $32.8 \pm 1.1$ & $25.1 \pm 1.3$ & $22.7 \pm 1.3$ & $13.8 \pm 1.6$ \\
$\mathrm{U}$ & $4.5 \pm 0.2$ & $3.9 \pm 0.2$ & $3.2 \pm 0.2$ & $2.9 \pm 0.2$ & $6.8 \pm 0.1$ & $2.3 \pm 0.2$ & $3.0 \pm 0.2$ \\
$\mathrm{Al} / \mathrm{Sc}$ & $4449 \pm 156$ & $6126 \pm 401$ & $6275 \pm 400$ & $4310 \pm 230$ & $4660 \pm 241$ & $5274 \pm 213$ & $3113 \pm 112$ \\
\hline
\end{tabular}


TABLE 4: Mean concentrations ( $\mathrm{mg} \mathrm{kg}^{-1}$ unless $\mathrm{mg} \mathrm{g}^{-1}$ is indicated) of pottery and soil samples

\begin{tabular}{|c|c|c|c|c|c|c|c|c|c|c|}
\hline \multirow[t]{2}{*}{ Elements } & \multicolumn{5}{|c|}{ Pottery $(N=7)$} & \multicolumn{5}{|c|}{ Soil $(N=7)$} \\
\hline & Min. & Max. & Mean & SD & $\% \mathrm{RSD}$ & Min. & Max. & Mean & SD & $\% \mathrm{RSD}$ \\
\hline $\mathrm{Na}^{*}$ & 2.1 & 5.8 & 3.5 & 1.3 & 38 & 1.1 & 6.2 & 2.5 & 1.8 & 71 \\
\hline $\mathrm{Al}^{*}$ & 62.5 & 86.5 & 74.6 & 8.8 & 12 & 34.6 & 84.6 & 70.1 & 18.0 & 26 \\
\hline $\mathrm{K}^{*}$ & 8.9 & 23.2 & 16.9 & 4.7 & 28 & 11.0 & 13.5 & 12.0 & 0.8 & 7 \\
\hline $\mathrm{Ca}^{*}$ & 7.6 & 14.4 & 10.8 & 2.5 & 23 & \multicolumn{5}{|c|}{ - Not measured - } \\
\hline $\mathrm{Sc}$ & 12.7 & 21.2 & 15.7 & 2.9 & 19 & 8.1 & 26.7 & 18.1 & 6.4 & 36 \\
\hline $\mathrm{Ti}^{*}$ & 3.6 & 8.2 & 6.2 & 1.7 & 27 & 3.1 & 7.8 & 5.6 & 1.4 & 25 \\
\hline $\mathrm{V}$ & 58.0 & 116.9 & 84.3 & 20.3 & 24 & 44.8 & 120.0 & 75.6 & 28.5 & 38 \\
\hline $\mathrm{Cr}$ & 61.8 & 143.9 & 80.1 & 29.7 & 37 & 46.4 & 193.0 & 105.1 & 59.5 & 57 \\
\hline $\mathrm{Mn}^{*}$ & 0.47 & 2.7 & 0.97 & 0.77 & 80 & 0.33 & 2.1 & 1.0 & 0.59 & 59 \\
\hline $\mathrm{Fe}^{*}$ & 34.9 & 58.0 & 45.2 & 9.0 & 20 & 24.9 & 61.3 & 45.8 & 16.5 & 36 \\
\hline Co & 5.0 & 10.7 & 7.3 & 2.0 & 28 & 9.0 & 21.2 & 15.7 & 5.1 & 32 \\
\hline $\mathrm{Ga}$ & 9.8 & 13.9 & 11.6 & 1.2 & 11 & 7.9 & 28.8 & 16.6 & 8.8 & 53 \\
\hline As & 2.0 & 6.9 & 3.8 & 1.9 & 50 & 3.8 & 17.9 & 11.3 & 5.0 & 44 \\
\hline $\mathrm{Br}$ & 2.0 & 4.1 & 2.8 & 0.8 & 27 & 2.5 & 7.9 & 5.9 & 1.9 & 33 \\
\hline $\mathrm{Rb}$ & 55.5 & 188.7 & 110.2 & 47.3 & 43 & 65.3 & 150.0 & 101.6 & 29.9 & 29 \\
\hline Cs & 1.2 & 1.7 & 1.4 & 0.2 & 13 & 1.0 & 3.9 & 2.0 & 0.8 & 41 \\
\hline $\mathrm{Ba}^{*}$ & 0.36 & 1.62 & 0.63 & 0.45 & 71 & 0.29 & 0.6 & 0.45 & 0.11 & 24 \\
\hline $\mathrm{Hf}$ & 8.1 & 13.2 & 10.9 & 2.1 & 19 & 9.2 & 17.0 & 12.8 & 3.0 & 23 \\
\hline $\mathrm{Th}$ & 13.8 & 38.2 & 25.7 & 8.4 & 33 & 15.4 & 39.0 & 25.3 & 7.7 & 30 \\
\hline $\mathrm{U}$ & 2.3 & 6.8 & 3.8 & 1.5 & 40 & 1.2 & 2.4 & 1.7 & 0.4 & 25 \\
\hline
\end{tabular}

$* \mathrm{mg} \mathrm{g}^{-1}$

ments of seven soil samples (column 11, Table 4) vary in the range of $23-71 \%$ (except $7 \%$ for $\mathrm{K}$ ). The observed large scatter suggests that the origin/source of these pottery as well as soil samples may not be the same.

For the preliminary information on provenance studies, the elemental concentration ratios of the two non-volatile elements $\mathrm{Al}$ and Sc were evaluated for soil (Table 2) and pottery (Table 3) samples under study. The concentration ratios of $\mathrm{Al}$ to $\mathrm{Sc}$ in pottery samples are expected to remain constant during pottery making process as well as afterwards withstanding wear and tear as they are non-volatile elements. The ratios of $\mathrm{Al}$ and $\mathrm{Sc}$ values of seven soil samples are shown in Figure 2. From the histogram of concentration ratios, inter-site distance grouping of the soil samples was done and they fall into four groups: (i) $\mathrm{S} 1$ and S2; (ii) S3, S4, and S5; (iii) S6; and (iv) S7.

Although the number of samples is less, it is apparent that they (soil samples) belong to four distinct groups. In view of this, to validate the visual grouping, the results were subjected to cluster analysis using STASTISTICA 5.1 statistical package. ${ }^{1,5}$ We have attempted to group these samples by considering some key elements namely $\mathrm{Rb}, \mathrm{Cs}, \mathrm{Ba}, \mathrm{Sc}, \mathrm{Cr}, \mathrm{Mn}, \mathrm{Fe}, \mathrm{Co}$,

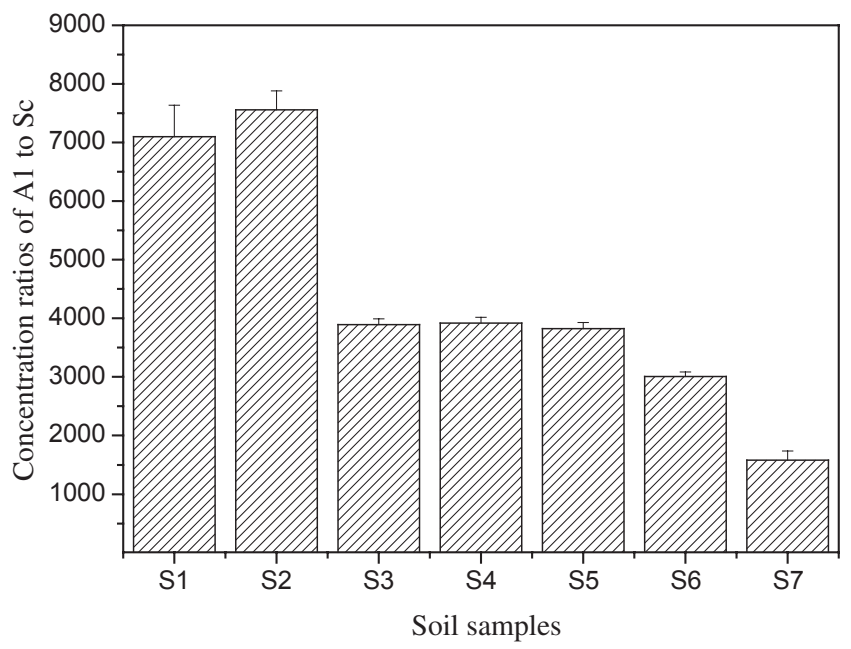

Figure 2. Histogram of concentration ratios of $\mathrm{Al}$ to $\mathrm{Sc}$ for seven soil samples. and Hf. Sodium and K were excluded as they are expected to be mobile during weathering process. The cluster analysis dendogram of seven soil samples are shown in Figure 3. The cluster analysis also supports the above finding that they belong to four groups. The cluster analysis is based on the calculation of the distances between the points representing the samples in the principal axes. The lengths of the links in the dendogram are proportional to the distances between the groups of the samples. From the Figure 3, it is clear that grouping by both methods lead to similar conclusion and thus validated our method of establishing provenance. Further the percentage deviations between two same and different group samples were carried out. The normalized \%deviations of concentrations of all elements of S1 with respect to corresponding elements in S7 belonging to farthest locations are in the range of $11-155 \%$ except for $\mathrm{Ga}(5 \%)$ e.g., $11.1 \%$ for $\mathrm{V}$ and $155 \%$ for As. The normalized \% deviations of S1 with respect to S7 were arrived at by dividing difference between $\mathrm{S} 1$ and $\mathrm{S} 7$ with $\mathrm{S} 7$ and then multiplying with 100 . In view of large scatter in the normalized deviation, it could be concluded that $\mathrm{S} 1$ and $\mathrm{S} 7$ are of different origin. Similarly, the calculated normalized \%deviations of concentrations of S4 with respect to S5 are within $10 \%$ for most of the elements, which suggest that they are of similar origin. It may be noted that S4 and S5 belong to nearby locations. The method of grouping the soil samples was in agree-

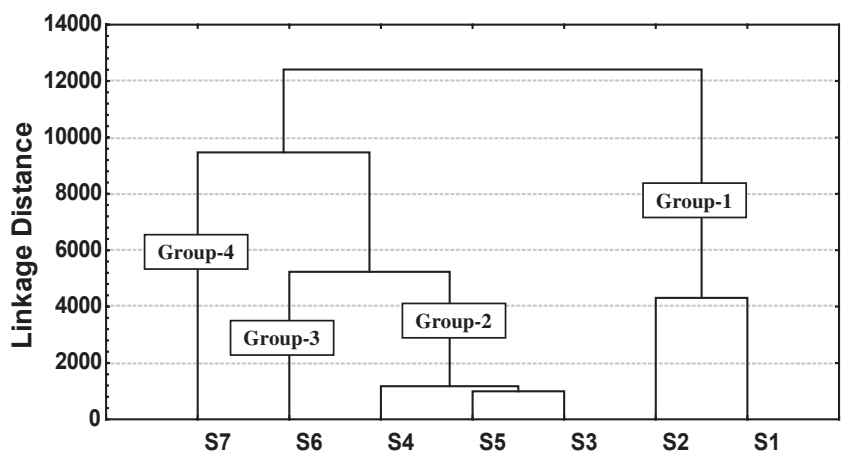

Figure 3. Dendogram of seven soil samples obtained by cluster analysis using nine key elements ( $\mathrm{Sc}, \mathrm{Cr}, \mathrm{Mn}, \mathrm{Fe}, \mathrm{Co}, \mathrm{Rb}, \mathrm{Cs}, \mathrm{Ba}$, and Hf). 


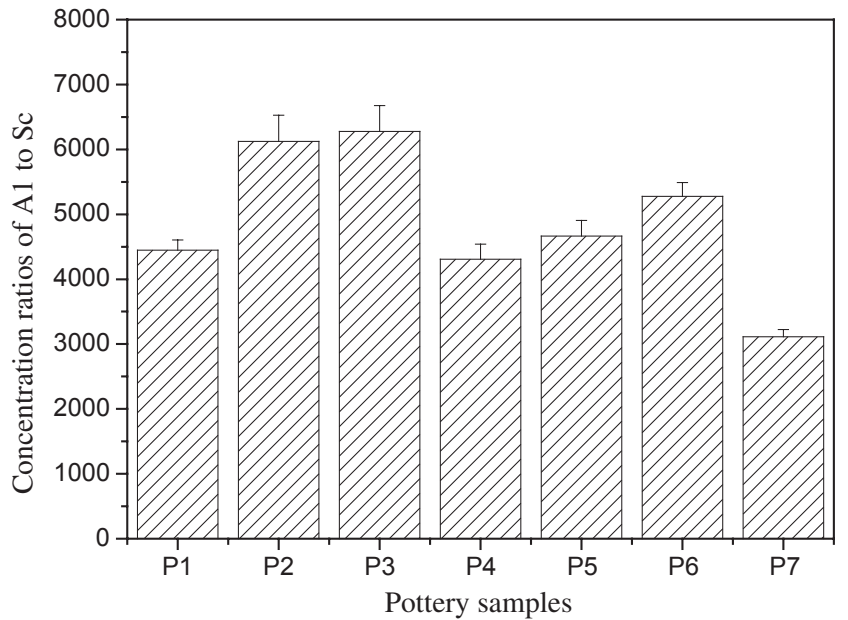

Figure 4. Histogram of concentration ratios of Al to Sc for seven pottery samples.

ment with our pre-knowledge of soil collection and vis-à-vis soil origin and thus validates our methodology of establishing provenance.

Similar analysis for pottery samples was carried for establishing grouping/provenance. Both concentration ratio values of Al to Sc and statistical cluster analysis results were used for the grouping of potteries. Histogram of concentration ratios of $\mathrm{Al}$ and Sc values is shown in Figure 4. From this figure, it appears that they fall into four groups as given here: (i) P1, P4, and P5; (ii) P2 and P3; (iii) P6; and (iv) P7. These results were subjected to statistical cluster analysis as done for soil samples. The dendogram of pottery samples obtained by cluster analysis is given in Figure 5. It is affirmed from the figure that they fall into same four groups as observed from the concentration ratios of Al to Sc. From Figure 1, it is clear that P3, P4, and P5 were collected from nearby locations. However, results of both concentration ratio values of $\mathrm{Al}$ to $\mathrm{Sc}$ and cluster analysis suggest that the pottery sample P3 differs from potteries of P4 and P5. This is taken as a clue that P3 may not have been prepared with the same source clay as that of P4 and P5. Further the normalized \% deviations of concentrations of all elements of P1 with respect to corresponding elements in $\mathrm{P} 7$, belonging to farthest locations, are in the range of $17-230 \%$. This confirms that P1 and $\mathrm{P} 7$ are of different origin. Similarly, the normalized $\%$ deviations for P4 with respect to P5 (belonging to nearby locations) are within $10 \%$ for many elements, which suggests that they are of similar origin.

\section{Conclusions}

INAA using reactor neutrons and high resolution $\gamma$-ray spectrometry was used to determine concentrations of 20 elements of significance in ancient pottery samples. Both the results of Al to Sc concentration ratios and statistical cluster analysis using nine key elements suggest that the pottery samples analyzed fall into four groups. Similar analyses on soil samples suggest that they also belong to four groups. Our approach of establishing provenance or grouping through elemental composition in conjunction with cluster analysis could be used for arriving at the source though the number of samples is less. Our future work on provenance study is being extended to more number of such samples collected from different places of Andhra Pradesh and its neighbouring states.

Acknowledgements. The authors are thankful to Dr. V. Venugopal, Director, Radiochemistry and Isotope Group, BARC and Dr. V.K. Manchanda, Head, Radiochemistry Division, BARC for their keen interest, encouragement, and

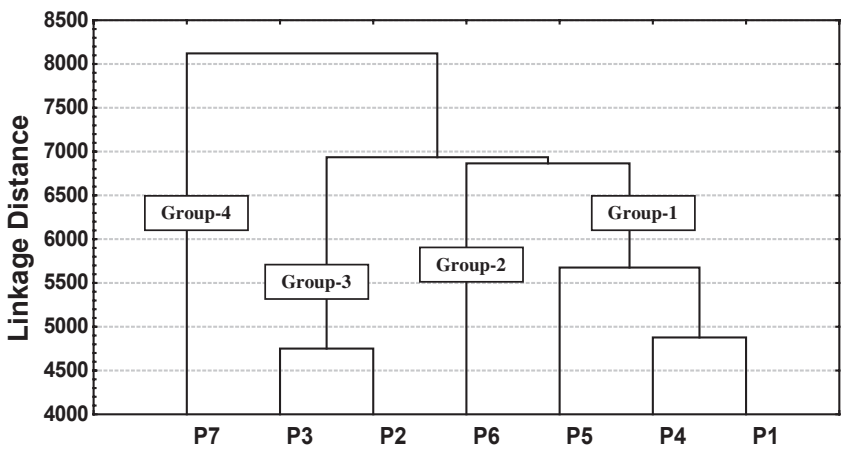

Figure 5. Dendogram of seven pottery samples obtained by cluster analysis using nine key elements ( $\mathrm{Sc}, \mathrm{Cr}, \mathrm{Mn}, \mathrm{Fe}, \mathrm{Co}, \mathrm{Rb}, \mathrm{Cs}, \mathrm{Ba}$, and Hf).

support for this work. Grateful acknowledgements are due to Dr. J. Kedareswari, Director, Department of Archaeology and Museums, Government of Andhra Pradesh for her support and interest in this work. Authors are thankful to the personnel of Apsara and Dhruva reactors for the cooperation during the irradiation of samples and also to Dr. R.K. Singhal and Shri Ajay Kumar, HPD, BARC for help in statistical analysis. Authors from GITAM Prof. N. Lakshmana Das and D.Partha Sarathi acknowledge UGC, New Delhi for the financial assistance under Major Research Project and UGC-DAE Consortium for Scientific Research, Mumbai for the financial assistance under "Archaeometry studies use INAA" since September 2006.

\section{References}

(1) J. W. Beal and I. Olmez, J. Radioanal. Nucl. Chem. 221, 9 (1997).

(2) H. R. Tykot, Proc. the international school of physics "Enrico Fermi" Course CLIV; Eds. M. Milazzo and M. Piacentini, (2004).

(3) F. Monroy-Guzman and P. Fournier, IAEA Technical Report Series No 416, International Atomic Energy Agency, Vienna, Chapter-9, 147 (2003).

(4) IAEA Technical Report Series No 416, International Atomic Energy Agency, Vienna, Chapter-1, 3 (2003).

(5) M. Balla, G. Keomley, and Gy. Rosner, J. Radioanal. Nucl. Chem. 141, 7 (1990).

(6) I. Rossini, J.C. Abbe, B. Guevara, and R. Tenorio, J. Radioanal. Nucl. Chem. 170, 411 (1993).

(7) D. Tenorio, M.G. Alamzan-Torres, F. Monroy-Guzman, N.L. Rodriguez-Garcia, and C. Longoria Luis, J. Radioanal. Nucl. Chem. 266, 471 (2005).

(8) W.D. James, R. L. Brewing, and H.J. Hafer, J. Radioanal. Nucl. Chem. 192, 109 (1995).

(9) M. Roumie, P. Reynolds, C. Atallah, E. Bakraji, K. Zahraman, and B. Nsouli, Nucl. Instrum. Methods B, 249, 612 (2006).

(10) E. H. Bakraji, J. Radioanal. Nucl. Chem. 264, 645 (2005).

(11) K. T. Biro, J. Radioanal. Nucl. Chem. 265, 235 (2005).

(12)E. Witkowska, K. Szczepaniak, and M. Biziuk, J. Radioanal. Nucl. Chem. 265, 141 (2005).

(13) C. Menninga, L Minc, M. D. Glascock, and C. Descantes C, J. Radioanal. Nucl. Chem. 266, 235 (2005).

(14) U.M.Vinagre Filho, R.M. Latini, A.V.B. Bellido, A. Buarque, and A.M. Borges, Brazilian J. of Phys. 35, 779 (2005).

(15) R. Acharya, Ph. D. Thesis, University of Mumbai, Mumbai, India (2000).

(16) R. Acharya and A.V.R. Reddy, IANCAS Bulletin, Indian Association of Nuclear and Allied Scientist, Bhaba Atomic Research Centre, Vol II (2), 111 (2003). 
(17) B. Subrahmanyam and E. Sivanagi Reddy, Dantapuram (An early Buddhist site in Andhra Pradesh) published by Department of archaeology and museums, Government of Andhra Pradesh, Hyderabad, India (2002).

(18) P.K. Mukhopadhyay, in: Proc. the symposium on Intelligent
Nuclear Instrumentation, Mumbai, India, 2001.

(19)F. De Corte and A. Simonits, J. Radioanal. Nucl. Chem. 133, 43 (1989).

(20)F. De Corte and A. Simonits, Atomic Data Nucl. Data Tables 85, 47 (2003). 